\begin{tabular}{|llllllllll}
\hline & $E$ & $D$ & $I$ & $T$ & $O$ & $R$ & I & $\mathbf{A}$ & $\mathbf{L}$ \\
\hline
\end{tabular}

\title{
Equity, Diversity, and Inclusion in the Massage Therapy Profession
}

Oluwakemi Balogun, MS4, University of South Carolina School of Medicine Greenville and Ann Blair Kennedy, LMT, BCTMB, DrPH, Executive Editor/Editor-in-Chief, IJTMB

University of South Carolina School of Medicine Greenville, Greenville, SC, USA

\begin{abstract}
It has been documented that there are disparities in who seeks massage therapy in the United States. Yet, there are few conversations about race and ethnicity of the massage therapists who provide these services. We must examine the diversity, equity, and inclusion within the massage therapy profession and consider how the profession can improve the landscape for clients/patients and for those who feel called to work within this field. Although the diversity of the profession and those who seek treatment are rarely discussed, this paper explores these issues and offers possible solutions to expand the diversity of the profession and patient population.
\end{abstract}

KEY WORDS: minority groups; ethnic groups; health occupations; health services accessibility; African Americans; massage therapy; primary health care

It is now the middle of June 2020, and it has already been quite a year. The Covid-19 pandemic caused most in the massage therapy profession to shut down in March/ April either due to statewide mandates, personal choice, employer decisions or a combination of these or other reasons. This time of uncertainty led to the launching of a new study, Project COPE: Chronicling healthcare prOviders' Pandemic Experiences, which is gathering insights to all types of health professionals' experiences, including massage therapists, during this unprecedented time in our history. This project also led to a new collaboration between a fourth-year medical student (OB) and her professor (ABK), one Black and one white.

At the beginning of our project we spoke about how during this time of shut down, one of the prime ways for individuals to manage stress (massage therapy) was not available. We suspected that this was impacting many, including this medical student who regularly receives massage therapy. It appeared that the uncertainty of when massage therapy practices would re-open was causing stress not only for patients/clients but also for the massage therapists who were out of work.

As we were beginning our work together, we also had a very frank discussion about race. While the research team was very interprofessional and multi-institutional, it was all white. While some aspects of diversity were clearly present, the main missing one was race. To be explicitly clear, we discussed how, while one new person on a team who is Black cannot be expected to provide perspectives for all Black people, even one person's ideas can help to shift the team. Our work together began in April and continued to progress. The pandemic continued but states began to open up. Students were again allowed in the clinical environment, and massage therapy was being offered again. And then it was May $25^{\text {th }}$, and George Floyd was murdered by a police officer, and the world seemed to finally take notice.

There seems to be a shift in society, and more and more people are beginning to wake up to the reality that Black and Brown people are treated differently in the United States. Princeton University has provided a link to sources concerning Black Lives Matter: Policing and Incarceration. (1) Included in the information they offer is a map of all the locations worldwide that have held protests, and as of June 14, nearly 3,500 protests have occurred since May 25, 2020. While it is long overdue, now we must examine the diversity, equity, and inclusion within the massage therapy practice and consider how those in the profession-from researchers, to educators, practitioners, and associations-can improve the landscape for clients/patients 
and for those who feel called to work within this field.

\section{United States Massage Therapy Patients/ Clients}

To begin, we need to consider who are receiving massage therapy in the US. Studies have indicated that there is both a gender and racial disparity in who seeks out massage therapy. (2-4) Results from the National Health Interview Survey (NHIS) which specifically asked questions about complementary and integrative health $(\mathrm{ClH})$ utilization in 2002, 2007, and 2012 showed there was a widening gap in who sought these services by race/ethnicity. (3) While non-Hispanic whites were increasing usage of $\mathrm{ClH}$, Hispanic adults and non-Hispanic Black adults saw a decrease in usage. (3) Considering the data from the 2012 NHIS only, Sundberg et al. found those who were living in the Western part of the United States, non-Hispanic white, and female were more likely to report receiving massage therapy within the last year compared to males, minority populations, and those living in areas other than the Western US. (2) The 2017 NHIS CIH supplement did not include questions about massage therapy. In 2019 and 2020, NHIS included questions about chronic pain management with massage as a management option; those data are yet to be reported. While the most recent data on massage therapy usage by race/ethnicity in the US is from 2012, the three time points do allow us to see a trend in the US showing racial and ethnic minorities accessing massage therapy services less often than non-Hispanic white individuals.

\section{Massage Therapists in the United States}

Who receives massage therapy though is only one piece of the equation; we also need to consider who is providing massage therapy. If Black people do not receive massage therapy as often as their white counterparts, then it is not too difficult to imagine that there may be a low number of Black massage therapists, especially when media reflects this disparity. For example, a quick investigation of "massage therapy" in Google images will overwhelmingly provide pictures of white women both giving and receiving massage. These images are a reflection of the profession and the patients who generally receive treatment.
This is further reinforced by other media that largely excludes the Black community and instead highlights the middle-upper class white woman surrounded by candles and flower pedals enjoying her day at the "spa." The bottom line is that representation matters. When you do not see yourself included in the field, you are less likely to pursue a career in the field. When you consider these factors alone, it is no wonder that there are not many black massage therapists in the field. When there is little experience in or exposure to the service, it is hard to imagine or realize the career opportunities available.

The US Bureau of Labor Statistics provides some information about the state of massage therapy in the country indicating that $83.6 \%$ of the profession are women and over $70 \%$ white. ${ }^{(5)}$ Compared to other professions that are either in a similar category (health-care support occupations) or similar field $(\mathrm{ClH})$, massage therapy is more similar in racial/ethnic demographics to chiropractors and physical therapy assistants than to other health-care support professions (Figure 1). (5) For massage therapy, these 2019 data show an increase of 3.3\% for Black/African Americans compared to a report of diversity in health occupations from 2011-2015 from the US Department of Health and Human Services. (6) The racial/ ethnic makeup of a profession is important because when there is a diverse workforce there can be improvements in patient satisfaction and access to care for those from minority populations. ${ }^{(6-9)}$

\section{Disparities in Treatment, Access, and Education}

From the above information it is clear that not only are there fewer Black people getting massage therapy but there are also fewer Black massage therapists. We believe these two observations are inextricably linked. The lower numbers of Black people receiving massage likely contribute to the low numbers of Black massage therapists in the field in a cyclical manner. The lack of personal exposure leads to fewer exploring or even realizing the professional opportunities available. Therefore, in order to begin discussing the lack of Black representation among massage therapists, we must first examine why Black people receive less massage. We think there are three main factors driving this observation: economics, education, and access. 


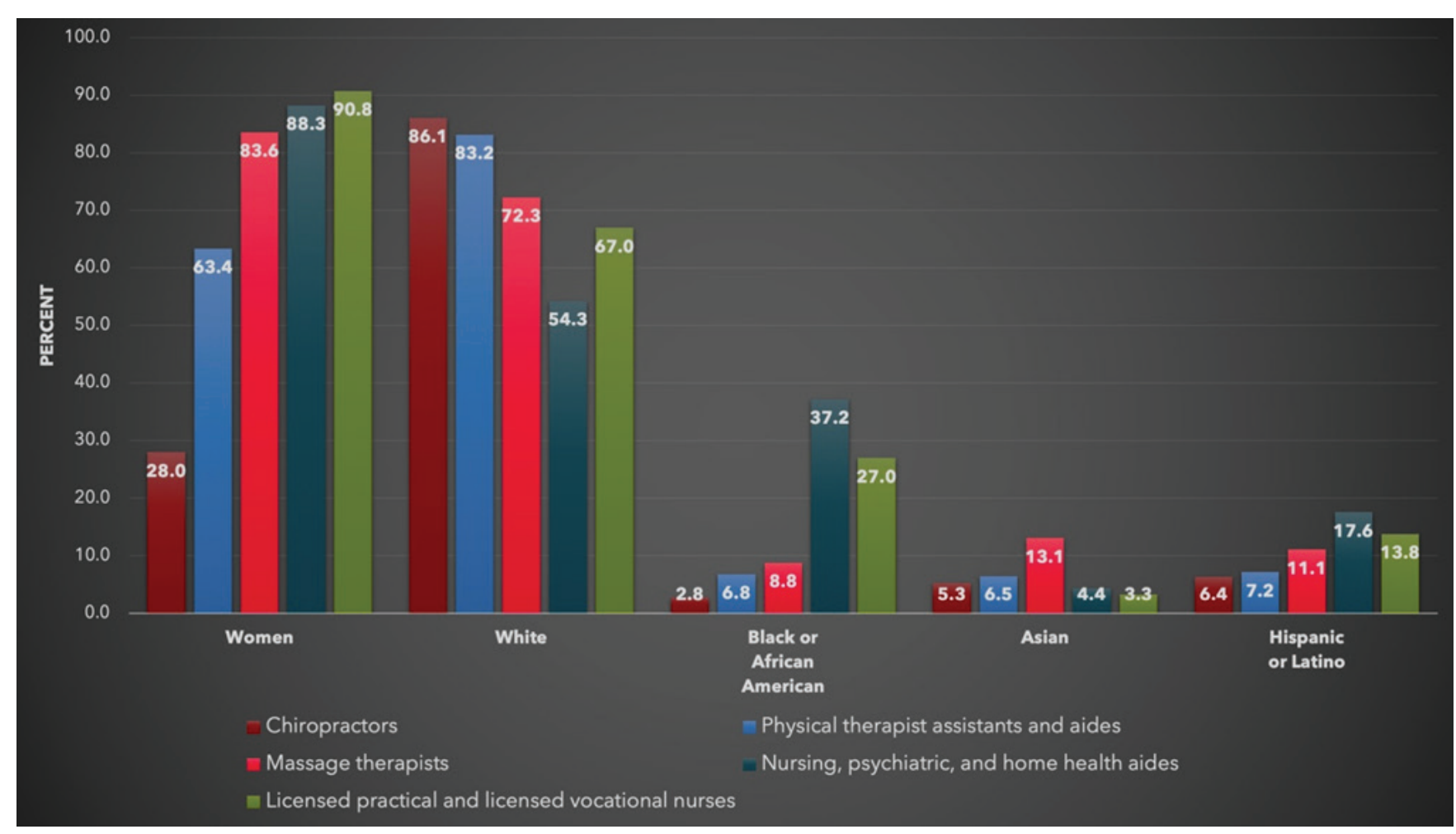

FIGURE 7. Percentage of individuals within select occupations in 2019 by gender and race/ethnicity from data the US Bureau of Labor Statistics ${ }^{(4)}$

First is economics. The Black community may not access massage therapy services as much as other communities because massage may be seen as a "Iuxury." In a recent podcast, Benny Vaughn explains his belief that in the African American community massage is something that "only rich people do..."(10) Therefore, massage may be a service many believe they cannot afford. Furthermore, Black communities are disproportionately economically disadvantaged (17) so they will be less likely to seek a service that is deemed as indulgent because they feel that they must prioritize "essential" needs.

Although, it has been reported that $21 \%$ of US adults received a massage in 2019, and that consumers believe in the efficacy of massage, the racial breakdown of these numbers is not clear. ${ }^{(12)}$ There is probably even more of a gap in education in the Black community, considering the tendency to have lower levels of health literacy in general when compared to white communities. (13)

Finally, Black people in the United States may be receiving less massage due to lack of access to treatment. The states with the highest concentration of massage therapy jobs (Hawaii, Colorado, Alaska, Washington, and Nevada) ${ }^{(14)}$ do not have a large population of African Americans. (15) The public may also not be aware of different types of locations where they might receive massage therapy as it is generally portrayed in the media as available in luxury/spa type locations. Many may not know how to access lower cost options such as franchises or independent massage therapists. Furthermore, there may not be accessible massage therapy practices in lower income neighborhoods, though that has yet to be explored.

While economics, education and access are just a few factors we believe may be contributing the trends described above, there may be additional factors at play. Unfortunately, these issues are not unique to massage therapy. We see similar patterns in medicine with only $5 \%$ of active physicians in the US identifying as Black or African American in 2018.(16) Barriers to matriculation and retention in medical education include but are not limited to the cost of applying to medical school, the lack of available guidance or mentorship and, finally, inadequate support from medical school administration. Could these same barriers exist in massage therapy educa- 
tion? To date, there are gaps in the literature pertaining to this very topic which provides opportunity for further investigation in order discover ways to support and increase diversity in the field of massage therapy.

\section{Solutions}

First for patients, one way to address the lack of education and access is to integrate massage therapy into more primary health-care settings, similar to the way physical therapy, occupational therapy, and speech therapy has been incorporated. Having your doctor discuss the benefits of massage therapy with you and then actually refer you to an in-house massage therapist could help drive home the point that massage therapy is indeed important. Stussman and colleagues did find that physicians are recommending $\mathrm{ClH}$ to patients and of the modalities recommended, massage therapy is recommended more than others. ${ }^{(17)}$ However, it is not known to whom these approaches are recommended. It may be that $\mathrm{ClH}$ and massage in particular are only recommended to white patients. Once there is more collaboration between massage therapy and medicine, the focus should then be placed on the affordability of services.

In the iterative process of increasing more Black patients, there also needs to be a way to increase the number of Black massage therapists. One way in particular could be to have increased presence and recruitment efforts at career fairs in predominantly Black high schools. There could also be more courses offered at technical/vocational education programs that could provide students more exposure to coursework in medical terminology, body mechanics, professional ethics, anatomy, and physiology. Some high schools offer vocational programs for students interested in early childhood education, computer science, cosmetology and more, and massage therapy could be integrated into these programs. Attention to the cost of massage therapy education will need to be considered within this context. These types of efforts could provide early exposure to the field, garner interest, and start students on the tract to licensure.

Once there are more Black massage therapists. there needs to be more outreach into the communities to let people know about the availability of services and therapists. In the aforementioned pod- cast, Benny Vaughn indicated that once he employed a Hispanic therapist in his clinic, the number of Hispanic patients increased exponentially. ${ }^{(10)}$ By increasing the diversity of the profession, we may also then increase the diversity of those who seek massage therapy.

Finally, as researchers and research participants, we need to track and continue to examine who is receiving and providing massage therapy based on multiple demographics including race/ethnicity. For those participating in research, it is vitally important that there are truthful answers when asked about race/ethnicity. For example, when asked about race/ethnicity a past responder in one of our studies selected the option "another/not listed". This participant then filled in the blank provided to expand on this selection with "there is only one race, the human race". Answers such as these do not allow us to track the success or failure of diversity and inclusion efforts.

The diversity of the massage therapy profession and those who seek massage therapy treatment are not topics that are often discussed, in our view. We need to consider who is at the (massage) table and who has been traditionally excluded. Once we start recognizing these inequities, we can work to dismantle them and bring others to the table for work and for treatment.

\section{COPYRIGHT}

Published under the CreativeCommons Attribution-NonCommercial-NoDerivs 3.0 License.

Corresponding author: Ann Blair Kennedy, LMT, BCTMB, DrPH, University of South Carolina School of Medicine Greenville, 701 Grove Road, Greenville, SC 29605, USA

E-mail: ExecEditor@IJTMB.org

\section{REFERENCES}

1. Knowlton S. Black Lives Matter: Policing and Incarceration [Home Page]. Princeton, NJ: Princeton University Library. Published July 1, 2020. Accessed July 2, 2020. https://libguides.princeton.edu/BlackLivesMatter-PolicingAndIncarceration

2. Sundberg T, Cramer H, Sibbritt D, Adams J, Lauche R. Prevalence, patterns, and predictors of massage practitioner utilization: results of a US nationally representative survey. Musculoskelet Sci Pract. 2017;32:31-37. 
3. Clarke TC, Black LI, Stussman BJ, Barnes PM, Nahin $\mathrm{RL}$. Trends in the use of complementary health approaches among adults: United States, 2002-2012. Natl Health Stat Rep. 2015;(79):1-16.

4. Escoto KH, Milbury K, Nguyen N, Cho D, Roberson C, Wetter D, et al. Use of complementary health practices in a church-based African American cohort. J Altern Complement Med. 2018;24(12): 1204-1213.

5. US Bureau of Labor Statistics. Employed Persons by Detailed Occupation, Sex, Race, and Hispanic or Latino Ethnicity [table]. Labor Force Statistics from the Current Population Survey. Published January 22, 2020. Accessed June 21, 2020. https://www.bls. gov/cps/cpsaat11.htm

6. U.S. Department of Health and Human Services, Health Resources \& Services Administration, $\mathrm{Na}$ tional Center for Health Workforce Analysis. Sex, Race, and Ethnic Diversity of U.S. Health Occupations (2011-2015). Rockville, ML: the Centre. 2017:14. Accessed June 17, 2020. https://bhw.hrsa.gov/sites/ default/files/bhw/nchwa/diversityushealthoccupations.pdf

7. Glover SH, Xirasagar S, Jeon Y, Elder KT, Piper CN, Pastides H. A human capital approach to reduce health disparities. J Health Disparities Res Pract. 2009;3(1):1-14.

8. Wakefield M. Improving the health of the nation: HRSA's mission to achieve health equity. Public Health Rep. 2014;129(1 Suppl 2):3-4.

9. Wilbur K, Snyder C, Essary AC, Reddy S, Will KK, Mary Saxon. Developing workforce diversity in the health professions: a social justice perspective. Health Prof Educ. 2020;6(2):222-229.

10. Luchau T, Lowe W. Thinking Practitioner Podcast. Episode 16: Benny Vaughn: Black Lives Matter [blog]. Lafayette, CO: Thinking Practitioner Podcast. Accessed June 17, 2020. https://advancedtrainings.com/ttp-podcast-16-benny-vaughnblack-lives-matter/
11. Wilson V, Williams J. Racial and Ethnic Income Gaps Persist Amid Uneven Growth in Household Incomes. Washington, DC: Economic Policy Institute. Published September 11, 2019. Accessed June 21, 2020. https://www.epi.org/blog/racialand-ethnic-income-gaps-persist-amid-unevengrowth-in-household-incomes/

12. American Massage Therapy Association. AMTA 2020 Massage Profession Research Report. Evanston, IL: AMTA; 2020. Accessed June 21, 2020. https:// www.amtamassage.org/globalassets/documents/ publications-and-research/2020-amta-researchreport-professional-version.pdf

13. Rikard RV, Thompson MS, McKinney J, Beauchamp A. Examining health literacy disparities in the United States: a third look at the National Assessment of Adult Literacy (NAAL). BMC Public Health. 2016;16(1):975.

14. US Bureau of Labor Statistics. Occupational Employment and Wages, May 2018: Massage Therapists. Occupational Employment Statistics. Washington, DC: US Bureau of Labor Statistics. Published March 29, 2019. Accessed June 21, 2020. https://www. bls.gov/oes/2018/may/oes319011.htm\#st

15. Anti-Discrimination Center. Segregated, Really Segregated, or Ultra-Segregated? New York: the Center. Published May 3, 2019. Accessed June 21, 2020. http://www.antibiaslaw.com/map-data-tool/ segregated-really-segregated-or-ultra-segregated-O

16. Association of American Medical Colleges. Diversity in Medicine: Facts and Figures 2019. Washington, DC: AAMC. Published 2020. Accessed July 8, 2020. https://www.aamc.org/data-reports/workforce/ interactive-data/figure-18-percentage-all-activephysicians-race/ethnicity-2018

17. Stussman BJ, Nahin RR, Barnes PM, Ward BW. U.S. physician recommendations to their patients about the use of complementary health approaches. J Altern Complement Med. 2020;26(1):25-33. 